\title{
Revista de Filosofía
}

ISSN: 0034-8244

http://dx.doi.org/10.5209/RESF.60197

\section{Ética, estética e historia en Dionisio de Halicarnaso: imitación y construcción de la tradición}

Iker Martínez Fernández ${ }^{1}$

Recibido: 25 de mayo de 2016 / Aceptado: 12 de diciembre de 2016

Resumen. La obra de Dionisio de Halicarnaso se ha dividido tradicionalmente en dos partes: por un lado, los tratados de retórica y, por otro, las Antigüedades romanas, narración de la historia de Roma desde sus orígenes hasta la Primera Guerra Púnica. No obstante, existe un elemento común entre los escritos retóricos y los históricos que da coherencia interna a toda la obra. Este elemento es la imitación, que Dionisio utiliza para vincular ética y estética al servicio de la construcción de la tradición del pueblo romano.

Palabras clave: Estética; ética; imitación; historia; tradición.

\section{[en] Ethics, Aesthetics and History in Dionysius of Halicarnassus: Imitation and Construction of Tradition}

\begin{abstract}
The work of Dionysius of Halicarnassus has been traditionally divided into two parts: first, treaties of rhetoric and, secondly, Roman Antiquities, the history of Rome from its origins to the First Punic War. However, there is a common element among the rhetorical and historical writings that gives internal coherence to the whole work. This element is imitation, which Dionysius used to link ethics and aesthetics at the service of building the tradition of the Roman people.
\end{abstract}

Keywords: Aesthetics; ethics; imitation; history; tradition.

Sumario: 1. Dionisio de Halicarnaso, profesor de griego en Roma; 2. La imitación del orador excelente: los principios del aticismo; 2.1. Los caracteres de la buena oratoria; 2.2. La composición literaria y su alcance más allá de la retórica; 2.3. La imitación como conditio sine qua non del comportamiento virtuoso; 3. Los principios del discurso histórico clasicista; 4. Las Antigüedades romanas como discurso histórico; 5. Conclusión: Imitación e Historia en la obra de Dionisio; 6. Referencias bibliográficas.

Cómo citar: Martínez Fernández, I. (2018): "Ética, estética e historia en Dionisio de Halicarnaso: imitación y construcción de la tradición", en Revista de Filosofía 43 (1), 9-26. 


\section{Dionisio de Halicarnaso, profesor de griego en Roma}

La única noticia que poseemos sobre Dionisio de Halicarnaso nos la ha transmitido él mismo al comienzo de las Antigüedades Romanas. (AR, I, 7:2-3), donde nos informa que llegó a Italia al final de la guerra civil, a mediados de la CLXXXVII Olimpiada, esto es, entre los años 30-29 a. C. ${ }^{2}$, y que permaneció en Roma durante un periodo de al menos veintidós años en los que se dedicó al estudio de la lengua y la cultura romanas. El traslado a Roma desde las distintas partes del imperio era frecuente en esta época y, más aún, el de griegos de cierta cultura cuya intención era la de enseñar retórica, pues, por una parte, las clases sobre esta materia solían impartirse en griego y no en latín y, por otra, al menos desde el siglo II a. C., los romanos de clases altas acudían e incluso protegían a los rétores griegos para que proporcionasen a sus hijos una cultura suficiente que los distinguiera socialmente ${ }^{3}$. Este hecho, que algunos autores han calificado de auténtico movimiento filohelénico, convirtió a Roma, durante los dos siglos siguientes y a pesar de las críticas por parte de algunos próceres romanos, en el centro de atracción de un buen número de intelectuales griegos que desarrollaron en la Urbs su actividad intelectual ${ }^{4}$.

Dado que no existen indicios que nos hagan pensar que Dionisio se acogiera a un patronazgo determinado, como sí ocurre en el caso de los grandes poetas latinos de esta época, podemos suponer que la enseñanza de la retórica debía funcionar como una verdadera profesión que, más allá de su amplia producción literaria, permitía a Dionisio ganarse la vida. Este hecho ha contribuido sin duda a considerar a nuestro autor como un crítico literario con pretensiones únicamente pedagógicas 5 . Ahora bien, que un crítico literario de cierta altura, tal y como se ha concebido tradicionalmente a Dionisio, no aluda en parte alguna de sus escritos a este foco literario emergente reunido en torno al emperador causa cierta extrañeza ${ }^{6}$. Como trataré de mostrar más adelante, esta circunstancia poco o nada tiene que ver con el azar; más bien resulta un claro indicador de la diversidad de objetivos entre la obra de este profesor de retórica y la de los poetas romanos, tanto en lo relativo al público al que se dirigen como a la finalidad de sus producciones.

Mucho se ha escrito sobre la adscripción filosófica de Dionisio sin que exista una opinión unánime al respecto. La ausencia de vínculo con la escuela epicúrea es clara $\mathrm{y}$, aunque no se encuentra en las obras que nos han llegado ningún ataque directo a Epicuro o a cualquiera de sus discípulos más conocidos, tal y como afirma Diógenes Laercio, no hallamos tampoco un vínculo o adhesión inquebrantable a ninguna de las doctrinas del Jardín ${ }^{7}$. No resulta tan clara su adhesión o rechazo al estoicismo, escuela de la que adopta algunos criterios que venían siendo defendidos por sus seguidores. En concreto, como tendremos ocasión de comprobar más adelante, Dionisio comparte con la stoa el vínculo entre la buena dicción y el justo fin, así como algunos de los planteamientos de los retóricos estoicos en torno a la claridad y la ambigüedad como defecto estilístico ${ }^{8}$. La adscripción de Dionisio al peripato ha

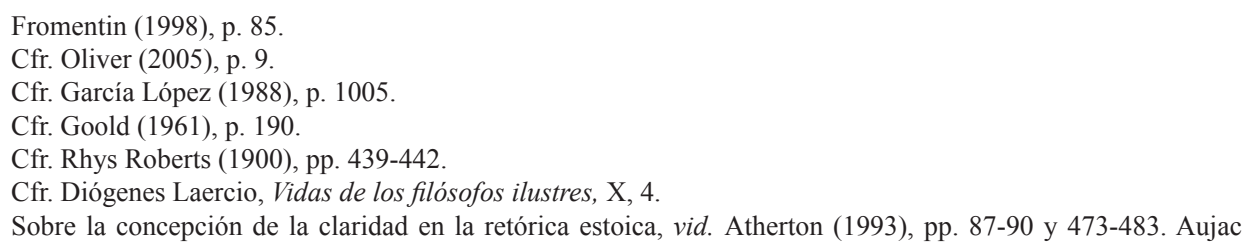


hallado un mayor número de defensores. Entre ellos, Bonner considera que la deuda que mantiene con esta filosofía es indudable y su influencia, directa en su teoría sobre la composición literaria e indirecta y subyacente en el análisis que realiza de los oradores áticos ${ }^{9}$. Otros autores han mostrado la proximidad de ciertas tesis de Dionisio con la retórica aristotélica, como el uso de determinada terminología o la similitud con algunas de las clasificaciones que propone ${ }^{10}$. La diversidad de criterio en relación con la adscripción filosófica o escolástica, de difícil solución, dado que no se trata de un debate de la época sino actual en el que probablemente todos los estudiosos señalados tienen parte de razón, muestra sin embargo que nos encontramos ante un hombre cuya amplia formación abarca materias diversas sin aparente conexión, aunque lo que se ha conservado parece remitir fundamentalmente a dos ámbitos: la retórica y la historia. Esta división es la que ha prevalecido en la literatura académica actual, por lo que se ha tendido a estudiar su obra desde el doble prisma estilístico e histórico, sin intentar el abordaje de los textos desde una perspectiva de conjunto ${ }^{11}$.

El estudio de la obra de Dionisio que se propone a continuación cuestiona seriamente que pueda mantenerse esta visión del profesor de Halicarnaso como crítico literario con pretensiones exclusivamente pedagógicas o como historiador de rigor más o menos discutible. Un análisis pormenorizado de todos los textos conservados que no descarte a priori la posibilidad de hallar en el conjunto de la obra una cierta coherencia interna requiere necesariamente delimitar un elemento unificador de temas tan diversos y aparentemente ajenos los unos de los otros como son los que Dionisio trata. Este elemento es, a mi juicio, el concepto de imitación, que Dionisio sitúa, como trataré de mostrar a continuación, como pilar que sostiene toda su construcción teórica. Sin una explicación detallada del papel que juega la imitación en la obra de Dionisio no es posible hacerse cargo del objetivo fundamental al que sirve: vincular ética, estética e historia para dar forma a una tradición romana que recoja lo mejor de la herencia del periodo griego clásico.

\section{La imitación del orador excelente: los principios del aticismo}

En el prólogo de su obra Sobre los oradores antiguos, y con objeto de justificar la elección de los autores que van a ser tratados, Dionisio compara el tipo de oratoria representada por ellos con aquel otro surgido con posterioridad a la muerte de Alejandro de Macedonia y que, según él, corre el riesgo de ocupar en su época todo el espacio público del discurso (politikoí lógoi). Se trata de la que quizá sea la descripción más detallada del asianismo que se conserva. La nueva oratoria se presenta en este texto como un verdadero engaño que trata de ocultarse al público por medio de una riqueza metafórica fuera de toda mesura. El texto resulta de gran interés como manifestación en negativo de algunas de las cuestiones que Dionisio pretende plantear en este trabajo. Así, frente a la oratoria de corte aticista, "noble",

(1978), pp. 16-17 considera a Dionisio un estoico; De Jonge (2008): 391-393, en cambio, opina que, aunque la obra de Dionisio recoge algunos aspectos de Crisipo, los argumentos de Aujac no resultan concluyentes.

9 Cfr. Bonner (1938), p. 258.

10 Para Artés (2013), Usher (1978).

11 Sobre la consideración de Dionisio como crítico literario, teórico de la retórica o historiador, cfr. Viljamaa (2003). 
"filósofa y sensata", su contrapuesta es calificada como "desvergonzada", "grosera", "vulgar" y "desagradable", llegándola a comparar con la amante insensata que arruina el hogar. Tal oratoria "acabó por hacer a Grecia semejante a las casas de esos hombres licenciosos y perversos" (OA, 1, 3-7).

El primer elemento al que conviene atender para situar una crítica realizada en términos tan duros es el contexto en el que esta se produce. En concreto, Dionisio va a proceder a una verdadera tarea de revitalización de lo que han de ser las virtudes de la dicción y la composición del discurso de acuerdo con lo que él considera el momento más excelente de la oratoria ateniense, que pone en relación con la Roma presente. La comparación entre estos dos momentos (la Atenas de los siglos V-IV a. C. y la Roma del siglo I a. C.) nos ofrece un claro indicio de la concepción que Dionisio maneja del principado de Augusto como apertura a un espacio nuevo y pleno de expectativas en la historia de Roma. Lo interesante de esta perspectiva es la funcionalidad que adquiere la dinámica de puesta en relación de dos periodos aparentemente tan diversos y alejados en el tiempo. Y es que, para Dionisio, sólo en la comparación se abre la posibilidad de determinar, de entre todos, los caracteres excelentes $(C P G .1,8)^{12}$. Téngase en cuenta que comparar es, en última instancia, relacionar dos o más elementos que, si bien parecen diferir en algunos aspectos, son similares en lo esencial. Dado que dicha esencia se encuentra en ocasiones oculta y requiere ser desvelada, conviene deshacerse de todo lo accidental que estorba al objetivo del alumno en aras de aprender las cualidades adecuadas. En definitiva, conviene delimitar con claridad los modelos que han de proponerse.

Muy vinculada a la presencia del elemento comparativo es el uso de la metáthesis, que se encuentra ya en los textos de Platón o Aristóteles, pero que Dionisio asume como práctica generalizada ${ }^{13}$. La metáthesis es un instrumento didáctico que permite reescribir cada texto original con una nueva formulación del mismo pensamiento, corregir faltas o errores de estilo o ilustrar alternativas posibles con igual valor que el original. En esta labor de manipulación textual, Dionisio suele atender a lo que considera es una mejor sonoridad o musicalidad de las frases, por lo que las comparaciones tienen como finalidad educar el oído y establecer criterios específicos del gusto. De estos dos rasgos -comparación y metáthesis- se infiere que la obra de Dionisio posee un carácter fuertemente pedagógico: el profesor de Halicarnaso escribe para los alumnos de retórica, esto es, para futuros oradores, aunque esto no impide que su expectativa de ser leído en círculos ajenos a la retórica sea un hecho más que probable, como tendremos ocasión de comprobar.

Con objeto de tomar la medida justa del alcance del proyecto dionisiano, conviene ahora poner en relación los dos elementos anteriores con los principios y virtudes de esa oratoria ática que pretende rescatar del olvido. Un primer elemento de este análisis va a consistir en la presentación de los caracteres que, según Dionisio, ha de ostentar el buen orador para posteriormente determinar el estilo y la forma de composición que considera adecuados para cada contexto, así como la delimitación de un modelo accesible para el estudiante de retórica. Por último, trataremos de clarificar los elementos que han de ser imitados y la mejor forma de hacerlo.

12 Como ha señalado Lockwood (1937), lo que otorga un valor preciso al método comparativo de Dionisio es la asunción tácita de la existencia de estándares críticos comunes para todas las producciones artísticas, ya sean escritas o no, como ocurre con la pintura, la escultura o la arquitectura.

13 Cfr. Platón, Fedro: 264d; Aristóteles, Retórica: 1367b-1368a, cit. en De Jonge (2005). Para un estudio completo de la metáthesis, vid. De Jonge (2005). 


\subsection{Los caracteres de la buena oratoria}

En la caracterización del buen orador, Dionisio toma como referencia a Lisias, aunque no le interesa tanto el orador concreto como las virtudes por él representadas, dignas de constituir un modelo. La más importante de todas es la pureza (katharmós) en el uso del griego, que ya en época de Dionisio equivalía sencillamente a Helenismo ${ }^{14}$. La propiedad al hablar no requiere el uso de un lenguaje técnico o figurado, sino el empleo de términos del lenguaje común (koinós) con su significado propio (kýrios). De ahí su rechazo al uso de metáforas, pues distorsionan el significado habitual de las palabras. La segunda virtud de la expresión es la claridad (saphéneia), fundamental para establecer un diálogo ausente de equívocos. Esta virtud se obtiene a través de la concisión (brachylogía) y de la capacidad de síntesis (strongýlos), que permite exponer los pensamientos de una forma condensada (Lis. 6, 3) ${ }^{15}$. La sencillez y claridad de la expresión no es incompatible con su viveza (enárgeia), por lo que la elaboración de los argumentos y su sucesión ha de combinar las anteriores características con un discurso ágil que mantenga en todo momento atento al auditorio. Otra virtud imprescindible en todo buen orador es su capacidad para la caracterización (ethopoiía) de los personajes de los que habla, lo cual requiere acomodar la expresión a su contexto específico ${ }^{16}$. Este elemento persigue la credibilidad del orador por medio de la imitación verosímil de los personajes que hace intervenir en sus discursos ${ }^{17}$. El decoro (tò prépon) se encuentra muy relacionada con la caracterización: cuando esta es correcta y el orador tiene en cuenta el auditorio al que se dirige, pues no es lo mismo dirigirse a un juez que a una asamblea de ciudadanos, modulará las formas de expresión de manera contenida y fiel para obtener una estructura compositiva personal y adecuada. Por último, Lisias sería para los aprendices de retórica ejemplo de gracia (kháris), que podría traducirse como la cualidad que otorga elegancia y personalidad al discurso.

Los tratados posteriores comparan, de acuerdo con el método anteriormente descrito, las cualidades de otros oradores con las de Lisias, añadiendo muy poco a las virtudes expuestas: Iseo es un imitador del genio de aquel, que únicamente destacaría por un estudiado seguimiento de los recursos técnicos (Is. 11, 1); de Isócrates, en cambio, destaca dos aspectos que lo convierten en ejemplo: un estilo florido que sabe enganchar al auditorio (ISO. 3, 5-6) y una inclinación hacia la filosofía que otorga brillantez a los temas que trata y que resulta muy adecuada para aquellos que pretendan hacer carrera política.

\subsection{La composición literaria y su alcance más allá de la retórica}

Dionisio se extraña de que la "ciencia de la composición" (synthetikés epistéme) haya pasado desapercibida para la mayor parte de los autores de retórica y filosofía, habida cuenta de su importancia para la construcción de discursos coherentes. Por ello, dedica un tratado completo a fijar los elementos que conducen a su perfección.

Una composición correcta ha de atender a la melodía, al ritmo, a la variación y al

14 Cfr. Atherton (1993), p. 483.

15 Atherton (1988): 401 considera que la brevedad y la concisión son las dos características que Dionisio aporta como novedades al listado tradicional de las virtudes retóricas.

16 La caracterización había sido tratada ya por Aristóteles en la Retórica, cfr. 1356a 5-15.

17 Cfr. Bruss (2013). 
decoro. Pero Dionisio no va a explicar estas funciones elaborando una sólida teoría, sino estableciendo exempla de cada una de ellas que puedan servir de referencia, esto es, va a explicar los modelos "en funcionamiento". Así, en relación con la melodía, Homero es el autor que ha de tomarse como referencia, si bien hay que tener en cuenta que existen algunas diferencias entre poesía y prosa, como el sometimiento a unas medidas más rígidas en el caso de la primera, que impiden un tratamiento homogéneo (CL. 26. 1-2). Asimismo, aunque Dionisio no deja de reconocer que la melodía puede conseguir que ambas se parezcan, eliminando algunas diferencias, su objetivo es el discurso en prosa, y a él va dedicado el estudio realizado sobre la composición.

En cuanto al ritmo, Dionisio presenta unas reglas para combinar de la mejor manera el ritmo óptimo con otros inferiores. Hace ya algunos años, Breitenbach puso en relación la concepción de la composición y, en concreto, del ritmo que presenta Dionisio con la que desarrolla Aristóteles en la Retórica ${ }^{18}$.El objetivo de Dionisio sería para Breitenbach meramente estético, razón por la cual vertería todas sus recomendaciones acerca del ritmo y la melodía con objeto de evitar la prosa plomiza o la poesía mecánicamente elaborada. El discurso agradará al oyente, no por el contenido que pretende transmitir, sino porque el discurso mismo, como la pieza musical, es un instrumento que proporciona placer. El placer al que haría referencia Aristóteles sería, en cambio, un placer intelectual derivado del aumento de conocimiento que proporciona el discurso como elemento de persuasión, por lo que todos los instrumentos de la composición, ritmo y melodía incluidos, se dirigirían a persuadir al oyente del contenido del discurso ${ }^{19}$. La postura de Breitenbach plantea la escisión entre un Aristóteles centrado en el contenido del discurso y un Dionisio que elabora preceptos puramente esteticistas. Sin embargo, no parece que este pretenda mostrar con sus modelos una ruptura entre forma y contenido, sino una relación muy estrecha entre ambos elementos. Hasta tal punto la melodía y el ritmo se encuentran vinculados al contenido, que todo tratamiento independiente de estos ámbitos conlleva resultados catastróficos para el discurso. Así, al tiempo que le otorgan belleza al conjunto, ritmo y melodía contribuyen a incrementar la de los actos que se narran o de los hombres que se describen en él; por el contrario, un ritmo innoble es inescindible de un acto innoble, y debe rechazarse.

Esta idea que subyace al planteamiento dionisiano sobre el estilo resulta aún más perceptible en la concepción de los dos elementos que nos resta por tratar: la variación y el decoro. La variación (metabolé) es una cualidad extraordinaria de la prosa que el orador debe usar con frecuencia. El discurso sin variaciones, además de aburrido, se encuentra lejos de la virtud de la adecuación, pues la realidad muestra cómo los hombres hablan de forma distinta o cómo situaciones similares avocan a reacciones diferentes según el contexto. La variación, como antes el ritmo y la melodía, no sólo es necesaria para agilizar y dar fluidez al discurso, sino para otorgar credibilidad al relato. Por su parte, Dionisio se refiere al decoro (tò prépon) como la disposición conveniente de todos los elementos de la composición ${ }^{20}$. Para explicar esta característica, toma de nuevo como ejemplo a Homero. En concreto, hace referencia al pasaje de la Odisea en el que el poeta describe los padecimientos

\footnotetext{
Aristóteles, Retórica, 1408b 20-1409a 24.

Cfr. Breitenbach (1911).

Cfr. Gray (1987), pp. 483-484.
} 
de Sísifo, condenado a una eternidad en la que sólo puede aspirar a repetir sin cesar la acción de subir rodando una piedra por una montaña y ver cómo vuelve a caer cuando ha llegado a la cima (Odisea, XI 593-596). A continuación, presenta todos los factores que Homero hace entrar en juego para describir el sufrimiento de Sísifo y analiza el valor de cada palabra, su ritmo y posición en el verso, el uso de las vocales largas para mostrar el trabajo lento y tedioso de la subida, o de las cortas, cuando se narra la caída de la piedra (CL. 20, 12-13). Lo que nos interesa destacar del comentario a este fragmento de la Odisea es precisamente esta suerte de identidad entre el hecho que narra el poeta y las palabras que utiliza para describirlo, como si la composición fuera el elemento que resta al hecho para que este sea real.

Es evidente, por tanto, que Dionisio está vinculando la grandeza de los hechos contados con la forma de contarlos. La cualidad del decoro permite, por tanto, que el discurso otorgue una realidad mayor a lo que el orador está diciendo, lo que impide calificar el decoro como algo meramente estético o formal. Y ello porque lo que se considera o no adecuado posee otras vertientes que también se ponen en juego en la composición literaria, como, por ejemplo, un determinado comportamiento moral. Esta conjunción se hace evidente en la configuración de Demóstenes como exemplum de orador ideal. A juicio de Dionisio, el orador ateniense compendia todas las virtudes expuestas en una sola persona, resultando un auténtico modelo en el aprendizaje del arte de elaborar discursos. Ahora bien, no se debe pensar que este Demóstenes es el individuo real, sino que nos hallamos ante un modelo tipificado cuya función consiste en apuntalar una idea de retórica, como lo han sido todos los oradores anteriormente tratados. Wooten ha observado cómo en la configuración de su Demóstenes, Dionisio prescinde de ciertos caracteres que sí fueron señalados por otros autores, tales como la velocidad en la narración, aludida por Hermógenes. El Demóstenes que recibimos aquí es, por tanto, un orador en cierta medida inventado que sirve a los intereses de su autor, por lo que se eluden en su construcción aquellos elementos o características del estilo del personaje real que no casan con los valores que pretende transmitir a sus lectores ${ }^{21}$. Dionisio nos presenta, por tanto, un modelo que debe imitarse, pero no cualquiera, sino uno que sirva "a quienes se ejercitan en el discurso público", esto es, un modelo para la política. El establecimiento de las virtudes del orador es meramente instrumental y coadyuva a esta finalidad políticomoral que implica poner en valor las virtudes anteriormente expuestas, que afectan, tanto a la composición de los discursos como al comportamiento del orador.

Teniendo en cuenta las consideraciones anteriores, resulta necesario cuestionar que estemos ante un mero crítico literario cuyas pretensiones se vean restringidas al ámbito de la retórica pues, tras esta exposición de caracteres en apariencia estilísticos, se halla, no sólo una idea determinada sobre la retórica, sino una opción moral y política concreta. Un análisis más detenido de su concepción sobre la imitación nos ayudará a entender mejor el alcance de su propuesta y profundizar en los elementos y valores que pretende transmitir al lector.

\subsection{La imitación como conditio sine qua non del comportamiento virtuoso}

En su interés por señalar lo que considera son las virtudes que ha de poseer todo orador, Dionisio ha utilizado a los Antiguos como instrumento para construir

21 Cfr. Wooten (1989). 
modelos que puedan imitarse. Su objeto, como ya se ha dicho, no es erudito, sino pedagógico y político; esto es, no consiste en analizar, como si se tratara de un filólogo, los textos que aporta la tradición. Esto, sin duda, lo hace; pero el foco está puesto en ofrecer a los jóvenes que estudian en las escuelas de retórica y que en el futuro tendrán encomendado el gobierno de la ciudad, exempla uirtutis que guíen su actividad política. La importancia que Dionisio concede a la imitación puede apreciarse con un simple vistazo a su obra: sus tratados tienden de continuo a analizar casos concretos, a señalar fragmentos que ejemplifican cualidades y a dirigir al lector hacia los modelos que propone. El método comparativo tiene, como ya se ha indicado, la función de destacar las virtudes que deben imitarse y hacerlo de una manera comprensible para los alumnos.

Los fragmentos que nos han llegado de su obra Sobre la imitación definen el término como "la actividad que mediante la contemplación continuada reproduce el modelo", o bien, ese "impulso del alma provocado por la admiración de lo que le parece bello" (Imit. I, 2). Su Epitome al Libro II presenta un resumen de todos los elementos que deben ser apreciados por el imitador. De ahí que establezca un auténtico canon de autores que han de imitarse en cada género: poesía, tragedia, historia, filosofía y oratoria. El canon es una tediosa relación de elementos vinculados a autores siempre griegos, casi todos ellos de los siglos V y IV a. C., con abundantes consideraciones de tipo estético y moral y sus correlativas recomendaciones para alcanzar las virtudes ya citadas. En realidad, Sobre la imitación es una guía para desenvolverse en el campo de la escritura aticista, en el entendido de que el lector no alcanza de manera automática la excelencia, sino que esta se obtiene con la práctica continuada y la ayuda del profesor, aspectos que permiten dilucidar en qué se ha de reparar cuando se entra en contacto con los hombres excelentes. En otro lugar expresa con claridad esta conjunción necesaria (Din. 7, 5-6).

Volvamos ahora al prólogo de la obra Sobre los oradores antiguos que citaba al comienzo de este apartado. Como se recordará, en él se hacía referencia a una clase de oratoria que, tras la muerte de Alejandro Magno, ocupó el lugar de aquella "antigua oratoria filosófica" que había dado un esplendor inusitado a Atenas. Las acusaciones que se vertían sobre ella la responsabilizaban, no sólo de la mediocridad de los discursos posteriores, sino de la corrupción moral de Grecia, que pasó a ser "semejante a las casas de esos hombres licenciosos y perversos" administradas "por una amante insensata que está allí para la perdición del hogar". Pues bien: frente a este tipo de oratoria, de consecuencias morales tan perversas, Dionisio propone todo el conjunto de virtudes áticas al que se ha hecho referencia. Estas resultan tan necesarias "para los que se ejercitan en la filosofía política" como para el resto de los hombres (philanthrópos), a los que el tema de qué sea lo mejor y más beneficioso para sus vidas no puede resultar ajeno $(O A .4,1)$. De manera que detrás de las reflexiones sobre la composición y el estilo se encuentra una auténtica propuesta de renovación político-moral que tiene un carácter universal, esto es, dirigida a la totalidad del Imperio, y que sitúa a la imitación en el centro de la fusión entre la Roma actual y ese pasado ático glorioso. El crítico literario se presenta, ahora sí, como un auténtico teórico de la política.

Un par de consideraciones más son necesarias para aclarar el alcance de la propuesta de Dionisio. En primer lugar, debe tenerse en cuenta que el uso de la imitación adopta aquí un papel, no tanto reproductor del modelo político ateniense, pues ello resultaría en Roma imposible en el momento en que Dionisio escribe, como 
de hacer partícipe a Roma de ese glorioso pasado. Imitar es para Dionisio participar de alguna manera en lo que se imita. Así, haciéndose partícipe de las virtudes clásicas, Roma hace suyo el legado de esta Grecia virtuosa que se nos presenta a través de sus oradores, historiadores y poetas más ilustres.

Una segunda consideración que conviene realizar es que la propuesta aticista de Dionisio debe incardinarse en elámbito de ese gusto helenístico y, más específicamente, romano por el regreso al pasado griego para convertirlo en clásico ${ }^{22}$. Una tendencia que se acentúa de manera muy clara en el principado de Augusto, pasando a integrarse en un proyecto más amplio de carácter político y moral patrocinado por el emperador. Que Dionisio sea parte de este proyecto es algo improbable, habida cuenta del aislamiento en el que trabaja con respecto al círculo cultural de Mecenas, pero es evidente que la preferencia aticista se encuentra en el ambiente y resulta determinante en su posicionamiento político-moral, posicionamiento que sólo puede comprenderse en profundidad analizando con mayor detenimiento su obra histórica, las Antigüedades romanas.

\section{Los principios del discurso histórico clasicista}

La exaltación de las virtudes áticas y el establecimiento de modelos de comportamiento político para el presente permite que, en el proyecto dionisiano, exista una comunidad de objetivos entre retórica e historia que hace que la diferencia entre ambas pueda ponerse en cuestión (CPG. 6, 11). Vida y discurso mantienen un nexo inescindible, por lo que, a través de la historia, se accede a la narración de los modelos personificados de virtud que nos proporciona el pasado. La historia es el cauce que proporciona, por un lado, exempla para la vida virtuosa y, por otro, la conexión entre los objetivos y valores sobre los que se asienta originariamente la comunidad política y el mundo actual. Si toda comparación requiere, al menos, dos términos, toda comparación histórica requerirá al menos dos momentos. Concebida la historia a la manera dionisiana, esto es, como narración de vidas ejemplares, uno de esos momentos - quizá el más importante- ha de ser el presente, abierto a las enseñanzas de los modelos de épocas anteriores. El momento del pasado ha de ser, a su vez, aquel en el que las virtudes que constituyen cada ejemplo sean nítidas y expresen con la mayor claridad los principios que impulsaron a la comunidad política a su apogeo ${ }^{23}$.No ha de extrañar, en consecuencia, que Dionisio acuda a los primeros gobernantes de Roma para explicar, con exempla, la gestación y el desarrollo de las virtudes romanas. Si tenemos en cuenta lo anterior, se comprenderá que no se vaya a abordar en este trabajo el debate sobre si Dionisio es o no mejor historiador que retórico ${ }^{24}$; interesa mucho más conocer de qué elementos se vale para dar forma a este gran discurso que es las Antigüedades romanas, las propuestas que quiere trasladar con su elaboración y, sobre todo, qué papel juega en él la imitación.

Esta concepción de la historia condiciona algunas decisiones que el autor ha de tomar antes de comenzar su relato. En concreto, tres: la elección del tema, la determinación del ámbito temporal al que va a referirse y los hechos que va a narrar.

\footnotetext{
Sobre esta cuestión, cfr. Bowersock (1979) y Wiater (2011)

Fornaro (1997), pp. 16-17

Cfr. Steuart (1921).
} 
En relación con el tema sobre el que se va a departir, este ha de ser "noble y agradable para sus lectores" $(C P G .3,2)$ : grandes hazañas o historias fabulosas donde el papel de los protagonistas es heroico o periodos de emergencia y grandeza de la ciudad son siempre más apropiados que los de decadencia. Sobre el periodo a tratar, el relato ha de comenzar por las causas y continuar por los hechos que se derivan de ellas. ( $C P G$. $3,8)$. La conclusión siempre ha de ser respetuosa con las razones que han llevado a los ciudadanos a comportarse de acuerdo con la virtud o, en su caso, justificativa de las razones por las que no tuvieron oportunidad de hacerlo. Por último, con la selección de los sucesos que se han de narrar se quiere hacer aquí referencia a lo que el de Halicarnaso denomina "estado de ánimo del historiador" $(C P G .3,15)$. Este es un factor de gran importancia para Dionisio, pues considera obligación del historiador presentar un relato benévolo y comprensivo de los problemas y los defectos de la patria: sólo en la medida en que afronte su obra con esta actitud será capaz de trasladar al público un discurso decoroso. De lo anterior se deduce que la intención última de nuestro autor no es establecer las condiciones que hagan del relato histórico un trabajo riguroso y más o menos objetivo, sino de atender siempre a la finalidad moral de la narración que se lleva a cabo en cada momento ${ }^{25}$.

En realidad, los elementos expuestos son la base sobre la que Dionisio identifica a su antagonista, que no es otro que Tucídides, al que admira, pero del que considera que ha de ser explicado con cuidado a los aprendices de esta retórica con finalidad política. La técnica comparativa no sólo muestra los modelos de excelencia, sino aquellos elementos que pueden actuar como exempla negativos. Más aún cuando los que hacen uso de ellos son personajes de cualidades y mérito reconocidos, como es el caso, pues el aprendiz podría confiar demasiado en el valor del modelo y reproducir actitudes no recomendables ${ }^{26}$. A juicio de Dionisio, Tucídides yerra en la decisión acerca de los tres elementos que ha de contener el relato histórico. En cuanto a la elección del tema, el ateniense escribe sobre una guerra desastrosa para su ciudad que merecería haber caído en el olvido $(C P G, 3,4)$. Heródoto, en cambio, convierte su historia en un ejercicio de recuerdo colectivo de logros extraordinarios alcanzados por los griegos, y no se olvida de dignificar a los bárbaros. Además, Tucídides inicia su relato en el momento en que las cosas comenzaron a ir mal para los griegos, "lo que no debería haber hecho un griego y mucho menos un ateniense". Las consecuencias de este error son muy graves desde el punto de vista del discurso histórico, dado que le lleva a culpar de la guerra a su propia patria, "pudiendo haberla atribuido a otras muchas causas" $(C P G .3,9)$. Tampoco acierta en la elección de los contenidos, pues, por un lado, utiliza el orden cronológico de exposición, lo que produce bruscos cortes en el relato derivados de una inflexible periodificación en estaciones -invierno y verano-, que oscurece la exposición y dificulta su seguimiento. Por otro, y esto le resulta a Dionisio más grave, su estado de ánimo "es severo, mordaz y rencoroso hacia su patria por el exilio" de veinte años que sufrió, lo que convierte su narración en un compendio de defectos de los atenienses descritos con extremado detalle sin mencionar prácticamente ningún acierto. Un juicio tan extremadamente negativo sobre el contenido de una obra ha de afectar necesariamente al estilo de su autor. De

25 Ello no significa que Dionisio no se preocupe, como se verá a continuación, por las fuentes o por la acumulación de datos que otorguen verosimilitud al relato.

26 En referencia a Platón, afirma: "Le censuro, no como a un hombre normal, sino como a uno destacado y cercano a la naturaleza divina" (CPG. 2, 2). 
ahí que Dionisio vincule la oscuridad y el carácter excesivamente enrevesado del lenguaje utilizado por Tucídides con sus bajas intenciones fruto del rencor ${ }^{27}$. Con ello demuestra de nuevo cómo en el proyecto dionisiano las diferencias entre forma y contenido, aunque puedan afectar al terreno de la veracidad de los hechos, tienden a difuminarse en beneficio tanto de la recuperación de la moral aticista como de una forma muy especial de entender las relaciones entre imitación e historia ${ }^{28}$. Veamos ahora cómo conjuga todos estos elementos en las Antigüedades romanas, el discurso de discursos histórico, moralizante y ejemplar sobre los orígenes de Roma.

\section{Las Antigüedades romanas como discurso histórico}

La crítica vertida sobre Tucídides con base en los elementos que ha de contener el discurso histórico resulta muy útil para analizar las Antigüedades romanas, la obra más ambiciosa y extensa de todas las que Dionisio escribió. Él mismo, en una suerte de prólogo dentro del Libro I, expone, siguiendo el esquema señalado en el apartado anterior, los motivos por los que ha elegido el tema, dónde se ha propuesto comenzar y los hechos que tiene intención de narrar.

Las Antigüedades romanas es, ante todo, el relato del nacimiento, crecimiento y apogeo de Roma. La intención de Dionisio es, en pocas palabras, mostrar que, partiendo de un pasado humilde que desembocó contra todo pronóstico en un estadio posterior de enorme éxito, Roma triunfó gracias a que sobre su base se encuentran varios elementos de origen griego. Este vínculo entre el pasado griego y la historia de Roma ha llevado en ocasiones a discutir si Dionisio se dirige a un público griego o romano. Antes de entrar en este debate conviene valorar cuáles son los objetivos que el de Halicarnaso persigue con su relato ${ }^{29}$. De momento, será suficiente considerar que la obra se dirige, como señala el propio autor, a todo aquel que "busque un entretenimiento tranquilo en sus lecturas de historia" $(A R$. I, 8, 3).

La historia de Dionisio comienza con "las más antiguas leyendas" sobre el origen de Roma que los historiadores anteriores a él omitieron "por ser difíciles de interpretar sin un gran estudio" y concluye con el inicio de la primera guerra púnica, esto es, en 265 a. C., que es el momento en el que parten las Historias de Polibio ( $A R$. I, 8, 1). La narración incluye las guerras en las que Roma participó y las causas que las provocaron, así como las instituciones políticas que se dio la ciudad. Las formas de gobierno se analizan de manera minuciosa, así como sus beneficios y perjuicios $y$, en general, el lector tiene continuamente la percepción, como ya se ha puesto de manifiesto en ocasiones, de que sus valoraciones siempre tienen base en debates del momento en que Dionisio escribe ${ }^{30}$. En cualquier caso, la obra pretende narrar las

27 Cfr. Fox (2001), p. 83.

28 Este hecho me impide compartir la postura de Gabba (1991), que considera que el contenido de la crítica a Tucídides no tendría en cuenta que su obra va dirigida a la clase dirigente ateniense, mientras que Dionisio la aborda desde un punto de vista meramente estilístico.

29 Cfr. Plácido (1984), p. 16. Las apelaciones a un destinatario griego de la obra $(A R$. I, 4, 2 o $A R$. V, 8, 1), no determinan sin embargo que este sea exclusivo. Es más, como ha mostrado Hill (1961), Dionisio conoce la obra de los historiadores romanos contemporáneos, como Varrón o Livio, y también existen indicios de que podría conocer la Eneida. Él mismo da cuenta de algunos problemas, tan discutidos en la Roma del momento, como el de la manumisión de los esclavos (AR. IV, 24). Las Antigüedades romanas contienen además guiños constantes a la cultura romana del principado de Augusto.

30 Sobre las consideraciones en torno a lo que Dionisio opina sobre la dictadura y la tiranía y su recepción en la 
hazañas y acontecimientos decisivos de los orígenes de Roma e incluye abundantes variaciones temáticas y multitud de apelaciones al auditorio o a los lectores. La disposición del autor, a diferencia de la de Tucídides, es la de una persona agradecida por todo lo que Roma le ha dado $(A R$. I, 6, 5).

La narración histórica de Dionisio no está preocupada por la absoluta precisión de los hechos, siempre que de lo expuesto se deriven resultados apropiados a las circunstancias concretas de cada personaje que interviene en la acción ${ }^{31}$. El decoro y la necesidad de presentar lo ocurrido de manera que el lector pueda "engancharse" al relato tienen, por tanto, una importancia fundamental, no sólo en la exposición, sino en la determinación de los propios hechos. Basta con que la argumentación que presenta sobre la idoneidad de una tesis sea convincente; si lo es, los datos que pueden resultar contradictorios son apartados convenientemente y, aunque no se omiten, se relegan del ámbito de lo probatorio al de lo debatible ${ }^{32}$. En ocasiones, las conjeturas son más relevantes que los datos disponibles, sirviendo estos únicamente para sustentar a posteriori las deducciones derivadas de las mismas $(A R$. I, 34, 5). Otra forma de selección de las conclusiones es la de la tesis más motivada, que Dionisio emplea de manera habitual como si los argumentos estuvieran por encima de los hechos o de los documentos conservados (vgr. AR. I, 54, 3). En general, Dionisio no pide datos, sino razones a favor y en contra que avalen las tesis sostenidas. La historia, como el discurso que se pronuncia en público por el orador, entiende fundamentalmente de argumentos; por ello, no puede prescindir de la teatralidad necesaria para mantener despierto el interés del lector $(A R$. III, 18, 1). La consecuencia de esto es la reducción del peso de las conclusiones en favor del juego argumental, que en no pocas ocasiones se deja abierto animando al lector a que elija la opción que le resulte más verosímil. Esta concepción del relato histórico entra en discusión con la necesaria sujeción del historiador a la verdad que Polibio había planteado en sus Historias y que se basa en la narración de los acontecimientos desde un cierto distanciamiento, esto es, sin tomar partido, diríamos, "por los nuestros"33. Ello no supone que el historiador deba prescindir de toda interpretación de los acontecimientos -y Polibio, en efecto, no deja de valorar los hechos que expone- sino que la narración fiel de los mismos, teniendo en cuenta las dimensiones estructurales de la historia -tiempo, modo y causa- ha de prevalecer frente a otras consideraciones con objeto de que esta despliegue todas sus posibilidades. Nuestro autor busca, sin embargo, verosimilitud más que veracidad. Aunque en realidad se trata de términos confusos y de difícil diferenciación, pues ¿no es lo verosímil más real y, por tanto, más verdadero que lo increíble, aunque esto último se encuentre respaldado por multitud de datos? La verosimilitud dionisiana no es, por tanto, sino la forma que adopta el decoro (tò prépon) en el relato histórico. No hay distanciamiento, como en Polibio, sino exaltación de los comportamientos virtuosos y delación de los vicios de los protagonistas del pasado.

Fox ha presentado las Antigüedades romanas desde la óptica de la tensión entre lo verdadero y lo bueno. De acuerdo con esta interpretación, los personajes tratados por Dionisio no son lo que realmente fueron, sino lo que deberían haber sido

actualidad, vid. Kalyvas (2007). Se trata este asunto en AR. V, 70-74 y 77.

31 Cfr. Walker (1993), pp. 376-377.

32 Cfr. La narración del asesinato del rey Tulio Hostilio (AR. III, 35, 5-6). Otros ejemplos, en $A R$. III, 21, 1. A este respecto, sobre los vínculos entre retórica e historia, tanto en Dionisio como en otros historiadores romanos, vid. Cary (1937), que se refiere a las Antigüedades romanas como una mezcla "pilla" entre retórica e historia.

33 Cfr. Polibio, Historias, I, 14, 5-6. 
atendiendo a los criterios elementales de la corrección de su conducta. La pregunta no es, pues, cómo se comportó tal o cual personaje, sino cómo se habría comportado un hombre que se atiene a las normas propias del decoro en caso de haber estado en la situación concreta que se describe. La idea de verdad histórica se encuentra, por tanto, vinculada al bien moral que ha de perseguir el historiador ${ }^{34}$. En efecto, en las Antigüedades romanas el comportamiento de los personajes se encuentra siempre mediado por este interés moralizador que convierte sus actos en ejemplos de actuación válidos para todos los tiempos y, por tanto, también para el presente. Esta idea se encuentra muy relacionada con la benévola disposición que Dionisio solicita al historiador y a la que se ha hecho referencia anteriormente. Si este afronta su trabajo sin ánimo de revancha, los resultados tenderán a resaltar los comportamientos acordes con la virtud, con lo que el relato será más justo y, en consecuencia, más verosímil ${ }^{35}$. Dicho en otras palabras, la verosimilitud no es sino el modo en que el profesor de Halicarnaso resuelve en el relato histórico la tensión entre el ser y el deber ser, entre lo que realmente ocurrió en un pasado que ha dejado de formar parte de la memoria colectiva de un pueblo y la convicción profunda de que ese pasado constituyó, por su ejemplaridad, una edad de oro que merecería ser imitada en un presente incomparablemente más corrompido. Esta idea de la mayor altura del pasado frente al presente se aprecia en toda la obra, adoptando en ocasiones un tono cuasi programático, como cuando describe las medidas que tomó Rómulo como la conjunción entre buena disposición de los dioses, sensatez y justicia, que medían "la felicidad no por los más vergonzosos placeres sino por lo honroso" (AR. II, 18, 1); o cuando compara la forma circunspecta que tenían los antiguos romanos de relacionarse con los dioses, frente a las formas actuales corrompidas (AR: II, 19, 2). La verosimilitud así entendida abre a Dionisio la posibilidad de interpretar muchos de los acontecimientos que narra. La ausencia de datos o su imprecisión anima esta forma de construcción del discurso histórico. Así, cualquiera que se aproxime a lo que se ha conservado de esta obra, podrá apreciar cómo se encuentra impregnada de paralelismos entre las acciones, costumbres y ritos de la antigua Roma y las de los pueblos griegos ${ }^{36}$.

Los historiadores que han abordado el estudio de las Antigüedades romanas han buscado con frecuencia, no tanto el interés perseguido por Dionisio al vincular la historia de Roma con Grecia, sino si las comparaciones que aquel establece entre costumbres romanas antiguas y las griegas carecen o no de base ${ }^{37}$. A mi juicio, esta perspectiva olvida el objetivo final del autor, que no es otro que mostrar al público que las virtudes griegas clásicas son un modelo de conducta para aquellas ciudades que persiguen los más altos fines. Y la historia de Roma es el ejemplo de ello. Tan es así, que Roma ha conseguido superar las más altas aspiraciones políticas griegas

\footnotetext{
Cfr. Fox (1993), p. 37 y ss.

Esta idea se hace evidente en el tratamiento de algunas instituciones romanas clásicas $(A R$. II, 8, 3).

36 Ya desde el comienzo mismo del relato, Dionisio deja claro que lo que se está proponiendo en la obra es una lectura de la historia de Roma como parte de la historia de los griegos (AR. I, 89, 1). Esta lectura se lleva a cabo en los más diversos aspectos: el origen de la lengua ( $A R$. I, 90, 1), o de las instituciones (AR. II, 8, 1-2), entre otros. La "firme libertad de los romanos" sería una imitación de la libertad que practicaron los griegos ( $A R$. II, $16,1)$, y la legislación acertada de los mejores gobernantes, como Rómulo, también resulta de la inspiración helénica ( $A R$. II, 17, 1; II, 18, 1-2). El pueblo sabino podría ser, según Dionisio, griego (AR. II, 49, 4-5) y Numa Pompilio, un gran rey que condujo la ciudad hacia el progreso, sabino (AR. II, 58, 2). Lo mismo cabe decir del pueblo albano (AR. III, 63, 1). Los ejemplos, como puede comprobarse, son abundantísimos.

37 Cfr. a modo de ejemplo: Domínguez Monedero (1989) o Greaves (1998).
} 
(AR. II, 17, 1): frente a la cerrazón helénica que despreciaba lo extranjero, Roma toma la delantera a Atenas y Esparta por su capacidad de asimilar a los bárbaros y hacerles partícipes de unas instituciones y unas costumbres que, por ser las del mejor periodo de la historia de los griegos, deben ser imitadas. La historia y las instituciones romanas ofrecen, en consecuencia, a los pueblos conquistados un modelo de conducta para alcanzar la excelencia en la virtud; también a los griegos que, tras siglos de decadencia, han olvidado lo mejor de su tradición.

Paralelamente, como ha afirmado Gabba, Dionisio, al hallar en este desarrollo las virtudes propias de la cultura griega clásica, no estaría sino vinculándolas con las costumbres y tradiciones romanas más antiguas, esto es, con las mores maiorum ${ }^{38}$. Esta asimilación se hace, en efecto, evidente en los últimos libros de las Antigüedades romanas, en los que se contraponen las tradiciones constitutivas del pueblo romano con las de los griegos y se dan la vuelta en una auténtica transformación que vincula directamente la identidad griega con aquellos que portan las mores maiorum y a los griegos con los bárbaros $(A R \text {. XIV, 6, 5-6 })^{39}$.

Las Antigüedades romanas son, por tanto, una historia ejemplar, pues presentan modelos de comportamiento de hombres ilustres y, a la vez, un modelo de ciudad ideal que no sólo es posible, sino actual. Que siga manteniendo en su desarrollo un poder sin parangón en la historia de los pueblos dependerá de la perseverancia de sus ciudadanos y sus gobernantes en someter sus actos a las mores maiorum, ese constructo romano que Dionisio ha declarado, tras un largo discurso histórico en veinte libros, griego ${ }^{40}$.

\section{Conclusión: Imitación e Historia en la obra de Dionisio}

En la famosa distinción entre poesía e historia que Aristóteles lleva a cabo en la Poética, el filósofo macedonio declara que la poesía hablaría sobre lo necesario, esto es, lo general, aquello que al hombre, visto como personaje tipificado, le corresponde hacer o decir en cada situación concreta. En otras palabras, al poeta le corresponde narrar, en verso o en prosa, lo que debe ser; la historia, en cambio, trataría sobre lo que ha sucedido en concreto a un personaje real ${ }^{41}$. Esta clasificación se basa en la consideración de que la poesía tiene una naturaleza imitativa de la que carece la historia. El contexto de la Poética ofrece pocas dudas al respecto. Sin embargo, la diferenciación entre poesía e historia, pese a la influencia que tuvo en épocas posteriores, no siguió siempre la preceptiva aristotélica, ni siquiera en la Antigüedad. En efecto, como ha mostrado Gray, ya en el siglo III a. C. Duris de Samos escribe una historia de Grecia y Macedonia en la que la imitación adquiere un papel fundamental ${ }^{42}$.

Para Dionisio, la historia consiste en la imitación de los caracteres y emociones (ethôn te kaì pathôn mímesis) de los personajes $(C P G .3,18)$ y no sólo en la narración de los hechos concretos. La imitación se logra, como ya se ha visto, observando

Cfr. Gabba (1991), pp. 203-204.

39 Resulta muy interesante al respecto, el análisis que realiza Peirano (2010) de los discursos del rey Pirro y Fabricio, embajador romano, en el Libro XIX (AR. XIX, 13-18).

40 Sobre la obra de Tito Livio como constructo de las mores maiorum, cfr. Mas (2006): 304 y ss.

41 Aristóteles, Poética, 1451a 36-1451b 11.

42 Cfr. Gray (1987), p. 468. 
la regla del decoro y de la corrección, tanto de los argumentos en la composición de los discursos como de los comportamientos y acciones de los personajes de los que trata. El objetivo que se propone el relato histórico es presentar las situaciones, no como sucedieron, sino como hubieran sucedido siendo los protagonistas los que eran y estando en el contexto en el que se encontraban. La imitación es, pues, para el de Halicarnaso, parte de una visión más amplia de la producción de la verdad histórica. De ahí su valor pedagógico fundamental -como ya lo tuvo en otro tiempo la poesía- para los ciudadanos y, sobre todo, para los políticos ${ }^{43}$. Por este motivo, parece claro que la crítica a Tucídides a la que se ha hecho referencia anteriormente ha de entenderse en sentido político; las cuestiones estilísticas únicamente dan pie a identificar con precisión el objetivo, pues se parte del supuesto de que Tucídides es el historiador más digno de ser imitado. La insistencia en la exposición de sus errores siempre desemboca en el hecho de que no representa los valores aticistas tal y como los expone Dionisio. Teniendo esto en cuenta, no nos puede extrañar que Dionisio evalúe las obras de Heródoto y de Tucídides como auténticas creaciones poéticas en el sentido que Aristóteles concedía a este término ( $C P G .3,21)$. Pues, al igual que la poesía, la historia, imitando la forma de comportarse de los personajes de los que trata, también crea modelos que pueden imitarse. De manera que Dionisio, con su historia ejemplar, dinamita en cierta medida, como más adelante lo hará de manera más explícita la Segunda Sofística, los dos términos que Aristóteles presenta como definitorios del género histórico y el poético, afirmando que también la historia, en tanto que imitación, ha de ocupar un papel central en la educación de la ciudad ${ }^{44}$.

Ahora bien, las Antigüedades romanas también se presentan a sí mismas como un exemplum para los que quieren elaborar discursos históricos con arreglo a los criterios que se encuentran recogidos fundamentalmente en su ensayo Sobre Tucídides y en la Carta a Pompeyo Gémino. La obra nos reporta, en consecuencia, un segundo modelo: el del relato histórico dotado de los caracteres que se han venido señalando a lo largo de este trabajo y dirigido a aquellos que tengan intención de narrar sucesos que merezcan ser recordados como ejemplo de vida. El papel central del hecho imitativo en la obra de Dionisio sirve además de enlace de lo que a nuestro juicio son las dos propuestas que contienen las Antigüedades romanas. La primera, dirigida a Roma, hace de su historia un modelo de virtud y presenta su proyecto de futuro en un contexto griego. Imitándose a sí misma, por medio de la observación de las mores maiorum, cuya asimilación con las virtudes áticas ya conocemos, Roma mantendrá e incluso incrementará su poder. La segunda propuesta se dirige a los griegos de su tiempo y confirma que el retorno a los valores clásicos de lo mejor de su tradición requiere seguir el modelo de Roma. Se presenta así un proyecto romano para Grecia, que ha de imitar la historia de Roma si pretende aspirar a ser considerada griega de nuevo. Imitación e historia son, por tanto, términos inseparables en este proyecto dionisiano de recuperación de las virtudes clásicas que quiere tener continuidad en la poderosa Roma imperial.

En conclusión, Dionisio elabora, bajo el velo de una aparente crítica literaria, un proyecto de auténtica renovación moral y política acorde con el nuevo tiempo que se inicia con el principado de Augusto. Dicho proyecto prescribe la adopción

43 Cfr. Fox (1993).

44 Cfr. Cassin, B. (2008), pp. 276-277 habla de una "retórica historizante" de la Segunda Sofística frente a la retórica filosófica de la primera. 
de ese constructo que da como resultado lo que nuestro autor considera virtudes áticas de los siglos V-IV a. C., representadas en autores tipificados, como fin de todo gobierno que pretenda alcanzar los más altos logros. El instrumento que permite salvar la distancia entre ambos periodos es la imitación, centro sobre el cual gravita la definición de las virtudes romanas que deben orientar la política del futuro. Dionisio define el discurso político y cultural de Roma imitando a Grecia; pero el resultado de este hecho imitativo es un producto específicamente romano y, para nuestro autor, superior al griego. De ahí que este profesor de Halicarnaso, que vive y piensa en Roma y desde Roma, represente quizá como ningún otro el alcance que, desde el punto de vista político y literario, tuvo la imitación en ese mundo complejo y fragmentado que denominamos Helenismo y que va a convertirse en los siglos inmediatamente posteriores en un juego de tradiciones que alcanzará su punto de inflexión durante la Segunda Sofística, donde la imitación desarrolla un grado extremo de complejidad. En la intersección entre el mundo helenístico y la gestación del Imperio Romano, Dionisio es capaz de tomar un hilo que nos conduce a una compleja madeja en la que se unen multitud de elementos entre los que cabe destacar la definición de lo clásico y su papel como instrumento de articulación sociopolítica, así como la definición de Grecia y el papel que ha de tener para la construcción de la tradición romana, temas que serán posteriormente convocados una y otra vez en la historia del pensamiento occidental.

\section{Referencias bibliográficas}

Artés Hernández, J. A. (2013): “ $\lambda \varepsilon ́ \xi 1 \zeta$ in Dionysius of Halicarnassus' writings on rhetoric", Rhetorica: A Journal of the History of Rhetoric, Vol. $31 \mathrm{~N}^{\circ}$ 4, pp. 372-387.

Atherton, Catherine (1993):The Stoics on ambiguity, Cambridge University Press, Cambridge. Atherton, Catherine (1988) "Hand over Fist: The Failure of Stoic Rhetoric", The Clasical Quaterly, Vol. 38, № 2, pp. 392-427.

Aujac, Germaine (1978): "Introduction" Denys d'Halicarnasse. Opuscules Rhétoriques, Paris, Les Belles Lettres.

Bonner, S. F. (1938): "Dionysius of Halicarnassus and the Peripatetic Mean of Style", Classical Philology, Vol. 33, Nº3, pp. 257-266.

Bowersock, G. W. (1979):"Historical problems in late republican an Augustan Classicism", Le Classicisme a Rome. Aux Iers Siècles avant et après J.-C., Entretiens sur 1'antiquité classique, Vandoevres-Genève.

Breitenbach, H. P. (1911): "The Compositione of Dionysius of Halicarnassus Considered with Reference to the Rhetoric of Aristotle", Classical Philology, Vol. 6, №2, 163-179.

Bruss, Kristine S. (2013) "Persuasive Ethopoeia in Dionysius' Lysias", Rhetorica: A Journal of the History of Rhetoric, Vol. 31, No 1, pp. 34-57.

Cary, Earnest (1937) "Introduction", Dionysius of Halicarnassus. The Roman Antiquities, Cambridge, Massachusetts; London, England,Loeb Classical Library, Harvard University Press., pp. VII-XLVII.

Cassin, B. (2008): El efecto sofistico, Buenos Aires, FCE.

De Jonge, Casper C. (2005): "Dionysius of Halicarnassus and the Method of Metathesis", The Classical Quarterly, Vol. 55 na 2, pp. 463-480.

De Jonge, Casper C. (2008): Between Grammar and Rhetoric. Dionysius of Halicarnassus on Language, Lingüistics and Literature, Boston,Brill, Leiden. 
Dionisio de Halicarnaso (2005): Tratados de crítica literaria. Sobre los oradores antiguos. Sobre Lisias. Sobre Isócrates. Sobre Iseo. Sobre Demóstenes. Sobre Tucídides. Sobre la imitación. Introducción, traducción y notas de Juan Pedro Oliver Segura, Madrid, Ed. Gredos.

Dionisio de Halicarnaso (2001): Sobre la composición literaria. Sobre Dinarco. Primera Carta a Ameo. Carta a Pompeyo Gémino. Segunda Carta a Ameo. Introducción, traducción y notas de Guillermo Galán Vioque y Miguel Ángel Márquez Guerrero, Madrid, Ed. Gredos.

Dionisio de Halicarnaso (1984): Historia antigua de Roma. Introducción de Domingo Plácido. Traducción y notas de Elvira Jiménez y Ester Sánchez (4 vols.), Madrid, Ed. Gredos.

Domínguez Monedero, Adolfo J. (1989): “El tema de la colonización griega en las Antigüedades Romanas de Dionisio de Halicarnaso", Anejos de Gerión II, Madrid, Universidad Complutense.

Fornaro, Sotera (1997): Dionisio d'Halicarnasso. Epistola a Pompeo Gemino. Introduzione e Comento, Stuttgart-Leipzig, Teubner.

Fox, Matthew (1993): "History and Rhetoric in Dionysius of Halicarnassus", The Journal of Roman Studies, Vol 83, pp. 31-47.

Fox, Matthew (2001): "Dionysius, Lucian and the Prejudice against Rhetoric in History", The Journal of Roman Studies, Vol. 1, pp. 76-93.

Fromentin, Valèrie (1998): “Introduction générale" Antiquités Romaines, T. I, Paris, Les Belles Lettres.

Gabba, Emilio (1981): “True History and False History in Classical Antiquity”, The Journal of Roman Studies, Vol. 71, pp. 50-62.

Gabba, Emilio (1991): Dionysius and the History of Archaic Rome, Berkeley, University of California Press.

Goold, G.P. (1961): “A Greek Professorial Circle at Rome”, Transactions and Proceedings of the American Philological Association, Vol. 92, pp. 168-192.

Gray, Vivienne (1987): "Mimesis in Greek Historical Theory", The American Journal of Philology, Vol. 108, № 3, pp. 467-486.

Greaves, A. M. (1998): "Dionysius of Halicarnassus, Antiquitates Romanae 2.30 and Herodotus 1. 146", The Classical Quarterly, New Series, Vol. 48 N² 2, pp. 572-574.

Hill, H. (1961): "Dionysius of Halicarnassus and the Origins of Rome", The Journal of Roman Studies, Vol. 51, Parts 1 and 2, pp. 88-93.

Kalyvas Andreas (2007): "The Tyranny of Dictatorship: When the Greek Tyrant Met the Roman Dictator", Political Theory, Vo. 35, No 4, pp. 412-442.

Lockwood, J. F. (1937):"The Metaphorical Vocabulary of Dionysius of Halicarnassus", en The Classical Quaterly, Vol. 31, No 3/4, pp. 192-203.

Mas, Salvador (2006): Pensamiento romano. Una historia de la filosofía en Roma, Valencia, Tirant lo Blanch.

Mira Seo, J. (2009): "Plagiarism and poetic identity in Martial", The American Journal of Philology, Vol. 130, Nº, $567-593$.

Peirano, Irene (2010): "Hellenized Romans and Barbarized Greeks. Reading the End of Dionysius of Halicarnassus", Antiquitates Romanae, The Journal of Roman Studies, Vol. 100, pp. 32-53.

Rhys Roberts, W. (1900): “The Literary Circle of Dionysius of Halicarnassus”, The Classical Review, Vol. 14 N $^{\circ}$ 9, pp. 439-442.

Shutt, R. J. H. (1935): “Dionysus of Halicarnassus”, Greek \& Rome, Vol. 4, No 12, pp. 139150. 
Steuart, Ether Mary (1921): "The Earliest Narrative Poetry of Rome", The Classical Quarterly, Vol. $15 \mathrm{~N}^{\mathrm{o}} 1$, pp. 31-37.

Viljamaa, Toivo (2003): "Colon and Comma. Dionysius of Halicarnassus on the Sentence Structure”, en Swiggers, P. y Wouters, A., Syntax in Antiquity, Leuven, Paris, Dudley, pp. 163-178.

Walker, Andrew D. (1993): "Enargeia and the Spectator in Greek Historiography", Transactions of the American Philological Association (1974-), Vol. 123, pp. 353-377.

Weaire, Gavin (2002): “The relationship between Dionysius of Halicarnassus De Imitatione and Epistula ad Pompeium", Classical Philology, Vol. 97, Nº, pp. 351-359.

Wiater, Nicolas (2011): The Ideology of Classicism. Language, History, and Identity in Dionysius of Halicarnassus, Berlin/New York, De Gruyter.

Wooten, Cecil. W. (1989): "Dionysius of Halicarnassus and Hermogenes on the Style of Demosthenes", en The American Journal of Philology, Vol. 110, №4, pp. 576-588. 